\title{
Correction to: A critical narrative inquiry to understand the impacts of an overdose prevention site on the lives of site users
}

\author{
Abe Oudshoorn ${ }^{1 *} \mathbb{D}$, Michelle Sangster Bouck², Melissa McCann², Shamiram Zendo ${ }^{1}$, Helene Berman ${ }^{1,3}$, \\ Jordan Banninga ${ }^{2}$, Marlene Janzen Le Ber ${ }^{4}$ and Zayya Zendo ${ }^{1}$
}

\section{Correction to: Harm Reduct J (2021) 18:6} https://doi.org/10.1186/s12954-020-00458-0

After publication of the original article [1], the authors identified an error in the author name of Marlene Janzen Le Ber. The given name and family name were erroneously transposed.

The incorrect author name is:

$<$ GivenName>Marlene J.<GivenName>

$<$ FamilyName $>$ Le Ber $<$ /FamilyName $>$

The correct author name is:

$<$ GivenName $>$ Marlene Janzen $</$ GivenName $>$

$<$ FamilyName $>$ Le Ber $<$ /FamilyName $>$

The original article has been corrected. impacts of an overdose prevention site on the lives of site users. Harm Reduct J. 2021;18:6. https://doi.org/10.1186/s12954-020-00458-0.

\section{Publisher's Note}

Springer Nature remains neutral with regard to jurisdictional claims in published maps and institutional affiliations.

\section{Author details}

${ }^{1}$ Western University, London, Canada. ${ }^{2}$ Middlesex-London Health Unit, London, Canada. ${ }^{3}$ Centre for Research on Health Equity and Social Inclusion, London, Canada. ${ }^{4}$ School of Leadership and Social Change, Brescia University College, London, Canada.

Published online: 08 February 2021

\section{Reference}

1. Oudshoorn A, Bouck MS, McCann M, Zendo S, Berman H, Banninga J, Janzen Le Ber M, Zendo Z. A critical narrative inquiry to understand the

The original article can be found online at https://doi.org/10.1186/s12954020-00458-0.

*Correspondence: aoudshoo@gmail.com

${ }^{1}$ Western University, London, Canada

Full list of author information is available at the end of the article original author(s) and the source, provide a link to the Creative Commons licence, and indicate if changes were made. The images or other third party material in this article are included in the article's Creative Commons licence, unless indicated otherwise in a credit line to the material. If material is not included in the article's Creative Commons licence and your intended use is not permitted by statutory regulation or exceeds the permitted use, you will need to obtain permission directly from the copyright holder. To view a copy of this licence, visit http://creativecommons.org/licenses/by/4.0/. The Creative Commons Public Domain Dedication waiver (http://creativeco mmons.org/publicdomain/zero/1.0/) applies to the data made available in this article, unless otherwise stated in a credit line to the data. 